\title{
Safety in the operating theatre-a transition to systems-based care
}

\author{
Thomas G. Weiser, Michael P. Porter and Ronald V. Maier
}

\begin{abstract}
All surgeons want the best, safest care for their patients, but providing this requires the complex coordination of multiple disciplines to ensure that all elements of care are timely, appropriate, and well organized. Quality-improvement initiatives are beginning to lead to improvements in the quality of care and coordination amongst teams in the operating room. As the population ages and patients present with more complex disease pathology, the demands for efficient systematization will increase. Although evidence suggests that postoperative mortality rates are declining, there is substantial room for improvement. Multiple quality metrics are used as surrogates for safe care, but surgical teams-including surgeons, anaesthetists, and nurses-must think beyond these simple interventions if they are to effectively communicate and coordinate in the face of increasing demands.
\end{abstract}

Weiser, T. G. et al. Nat. Rev. Urol. 10, 161-173; published online 19 February 2013; doi:10.1038/nrurol.2013.13

\section{Introduction}

A century ago, Ernest Codman (Figure 1) was forced from his position as a surgeon at the Massachusetts General Hospital, Boston, USA, for heralding the measurement of outcomes as a foundation for clinical excellence. He understood that careful assessment and analysis of surgical results is essential for service improvement, the provision of safe and effective care, and the prevention of errors. This philosophy formed the foundation of an 'end results system'. In addition, Codman established the first morbidity and mortality conference to review rates of complications and deaths, and disseminate knowledge for preventing harm to patients. However, his ideas were considered radical and Codman was rejected by his peers and stripped of his clinical duties. He went on to found the American College of Surgeons (ACS) and the Hospital Standardization Program, the precursor organization of the Joint Commission, but never lived to see outcomes measurement implemented in any standard or rigorous way.

Surgical safety has made tremendous progress since Codman's time, but only recently has concerted attention been paid to the issues of safety and reliability in health care. In particular, the now-famous Institute of Medicine publication entitled "To err is human" galvanized the movement after reporting catastrophic death and complication rates attributable to medical care. ${ }^{1}$ Outcome evaluations are now routine at nearly all institutions with surgical capacity and numerous quality-improvement programs have been established to improve adherence to, and systematize the process of, care delivery. Despite these efforts, surgical harm continues to be a serious concern. In the USA, the rate

Competing interests

The authors declare no competing interests. of postoperative deaths per hospitalization was $1.14 \%$ in 2006-an improvement from 1.64\% 10 years previously. ${ }^{2}$ In The Netherlands, a review of 3.7 million surgical procedures at 102 hospitals over 15 years revealed a perioperative mortality rate of $1.85 \% .^{3}$ Most recently, Pearse et al. ${ }^{4}$ demonstrated greater-than-expected postoperative mortality rates in 28 European countries, with an overall mean inpatient death rate of $4 \%$. Crude mortality rates varied widely in this study, from $1.2 \%$ for Iceland to $21.5 \%$ for Latvia. The national postoperative death rate for major urologic surgical procedures, such as radical cystectomy, in the USA has been estimated at 1.5$2.9 \%,{ }^{5,6}$ with some low-volume centres demonstrating a 30 -day mortality rate approaching $5 \%{ }^{7}$ Furthermore, in developed countries, over $50 \%$ of the adverse events that occur in surgical patients are thought to be preventable. ${ }^{8,9}$ In more resource-constrained settings, this proportion is even greater; a recent study of over 15,000 hospitalized individuals in eight countries (Egypt, Jordan, Kenya, Morocco, Tunisia, Sudan, South Africa, and Yemen) demonstrated that almost one in ten surgical patients suffers an adverse event and, of these, more that $80 \%$ are preventable and $30 \%$ lead to patient death. ${ }^{10}$ With over 230 million operations performed worldwide each year, surgical safety is a public health priority (Box 1). ${ }^{11}$

As our understanding of the effect that preventative measures have on clinical outcomes has developed, so too has the complexity of surgical care. Few disciplines in medicine are as complex, therapeutic, or dangerous as surgery. And, although there are only a few ways for an operation to go well, there are hundreds of ways that it can go wrong. Technical failure is a concern, but small acts of omission and commission during the perioperative period have profound effects on end results (Figure 2). It is now clear that multidisciplinary teams
Stanford University

Medical Center,

Department of Surgery,

300 Pasteur

Drive S067,

Stanford, CA 94305

USA (T. G. Weiser).

Department of Urology, University of

Washington, VA Puget Sound Health Care System, 1660 South Columbian Way, Seattle, WA 98108, USA (M. P. Porter). Department of Surgery, Harborview Medical Center, 325 Ninth Avenue, Box 359796, Seattle, WA 98104, USA (R. V. Maier).

Correspondence to: T. G. Weiser tweiser@stanford.edu 


\section{Key points}

- Death occurs in the hospital following at least one in every 100 inpatient operations, with complications far exceeding this; up to $50 \%$ of complications following surgery are avoidable

- The science of quality improvement has led to recognition that placing blame for harm or errors on an individual likely misses systemic problems in care delivery

- Controlling risk factors is just one element of ensuring quality of care

- Communication and teamwork have a major role in improving the safety of surgical care

- Effective surveillance and measurement systems for evaluating compliance with care standards and outcomes of surgical therapy, as well as mechanisms for clinician feedback, are important for assessing quality and improving performance
It is clear that traditional mechanisms for ensuring appropriate and timely care are inadequate and antiquated. Thus, the idea of a systems-based model for health-care delivery has become more compelling. Systems-based practice focuses on the broader context of patient care within a health-care system, considering factors such as payers, delivery systems, provider organizations, and individual clinicians, as well as the patients and their families. One of the core competency expectations of US-based medical Residents, ${ }^{16}$ this approach demands that clinicians think beyond individual therapeutic tasks. Surgeons must understand and appreciate the context and environment within which patients receive care as errors occur, not only at the hands of individual clinical personnel, but also as a result of inherent weaknesses within the health-care delivery system. Given the coordination that surgery requires between different team members, mechanisms for ensuring safe high-quality care must address both the individual steps known to promote improved outcomes and the communication of information between all staff involved in the delivery of care. Although surgical care is indisputably complex, clear processes exist to promote safety and maximize outcomes. Many of these processes relate to the control and mitigation of risk factors, and the prevention of associated complications. This Review will outline a number of parameters for evaluating the quality of surgical care and explore some systems-based interventions that aim to improve teamwork, communication, and the evaluation of safety and outcomes.

\section{Anaesthetic monitoring}

One of the most important contributions towards the improvement of surgical safety was the development of anaesthesia standards. Originally developed in Boston, USA, the 'Harvard monitoring standards' for intraoperative anaesthesia-related care formalized a set of medical standards of practice that, ultimately, developed into a set of international standards endorsed by the World Federation of Societies of Anesthesiologists. ${ }^{17,18}$ In the developed world, these standards-which include stipulations regarding the continuous presence of a trained anaesthetist and the uninterrupted monitoring of oxygenation, ventilation, and perfusion-now seem so routine that it is easy to forget how radical these practices were 25 years ago. Along with the introduction of monitoring requirements, anaesthetic delivery mechanisms were standardized. Inhalational anaesthetic machines became redundant and safety features such as autolock mechanisms prevented lethal hypoxic gas mixtures from being delivered to the patient (Figure 3 ). With these simple developments, anaesthesia-related deaths have plunged. ${ }^{19}$ The most recent estimates suggest a 100 -fold reduction in anaesthesia-related mortality rates within the past 50 years, from 357 deaths per million anaesthetics prior to 1970 to 34 deaths per million anaesthetics at the turn of the $21^{\text {st }}$ century. ${ }^{20}$ However, anaesthesia-related mortality continues to be a major problem in the developing world, with rates as high as one death per 500 procedures. ${ }^{21}$ In part, this 
can be attributed to lack of professionalization, particularly the absence of basic monitoring equipment and recognized monitoring standards. To address this issue, a concerted effort is currently underway to establish pulse oximetry monitoring in every operating theatre in the world. ${ }^{22,23}$

Open communication between the surgeon and the anaesthetist is also critical, particularly when anaesthesia is essential to performing a safe surgical procedure. For example, adequate neuromuscular blockade is crucial during transurethral bladder tumour resection for patients who are at risk of obturator nerve stimulation and electrolytes should be monitored closely during transurethral prostatectomy. Compliance with these processes is now considered a minimum standard in the provision of safe, effective surgical care.

\section{Infection control}

Antibiotic prophylaxis is an essential component of preemptive infection control. Surgical site infections (SSIs) are responsible for approximately $20 \%$ of all healthcare-associated infections diagnosed in hospitals in the $\mathrm{USA}^{24}$ and affect up to $30 \%$ of postoperative patients in Europe, the USA, and Australia. ${ }^{25-28}$ Postoperative infections increase length of stay, hospital costs, and risk of mortality. ${ }^{29-32}$ The financial cost of SSIs varies tremendously, depending on the health-care system, type of operation, and extent of infection. ${ }^{33,34}$ In the USA, SSIs are responsible for an additional 1 million inpatient days and $\$ 1.6$ billion US dollars. ${ }^{35}$ In the UK, SSIs are associated with an estimated excess cost of $£ 1,594$ GDP per infection. ${ }^{25}$ More widely within the European Union, SSIs are thought to cost between $€ 1.5$ and 19.1 billion Euros per year. ${ }^{28}$

Convincing data support the use of prophylactic antibiotics for all gastrointestinal, oropharyngeal, vascular, open heart, obstetric, and gynaecological procedures, as well as orthopaedic prosthesis placement, spinal operations, and craniotomy. ${ }^{36,37}$ Although the absolute number of infections is relatively low for many of these procedures, the consequences of infection can be severe. Furthermore, there is evidence to suggest that certain procedures, such as herniorrhaphy and breast surgery, benefit from preoperative antibiosis. ${ }^{38} \mathrm{~A}$ useful summary of antibiotic recommendations for common urologic procedures can be found in the best practice statement on urologic surgery antimicrobial prophylaxis released by the American Urological Association (AUA). ${ }^{39}$ For example, a fluoroquinolone or trimethoprimsulfamethoxazole is sufficient prophylaxis for simple cystourethroscopy procedures when risk factors for infection (such as steroid use, advanced age, prolonged hospitalization, or immunodeficiency) are present.

Patients undergoing open or laparoscopic procedures that violate the urinary tract should be given a preoperative dose of a first-generation or second-generation cephalosporin, or an aminoglycoside (aztreonam in the setting of renal insufficiency) combined with metronidazole or clindamycin. Patients undergoing open or laparoscopic surgery that violates the gastrointestinal
Box 1 | Summary of recommendations for improving surgical safety

- Basic standards of quality and safety should be outlined and clearly understood and adhered to, with a mechanism in place to monitor compliance

- Team communication should be encouraged by the use of perioperative team briefings and checklists

- Measurement of process and outcome results should form a routine part of quality assurance; these results should be fed back to appropriate clinical staff, including surgeons, anaesthetists, and nurses

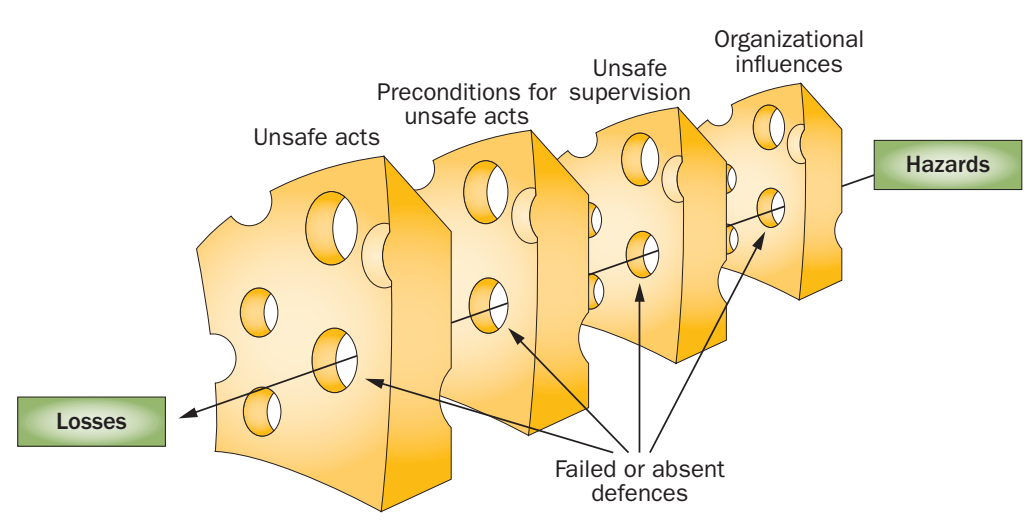

Figure 2 | The 'Swiss Cheese' model proposed by James Reason demonstrates how gaps in culture, defenses, barriers, and safeguards align and permit errors to propagate unchecked, leading to harm. ${ }^{167}$ Permissions to modify obtained from Cambridge University Press, Cambridge, UK.

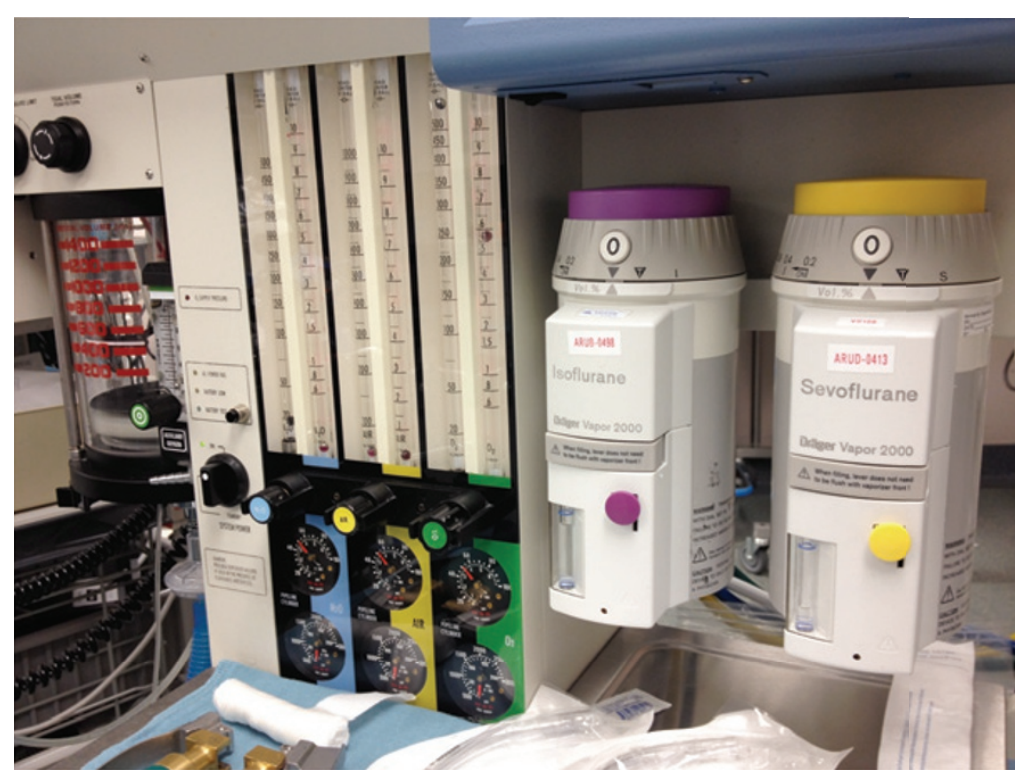

Figure 3 Anesthesia machines were engineered for safety, with multiple design elements demonstrated in this display. Vapour knobs are large, colour coded, and turn on and off in the same direction across the circuit. The nitrous knob is linked to the oxygen system to prevent hypoxic gas mixtures and disconnect alarms are present and audible.

tract should receive a second-generation or thirdgeneration cephalosporin, or an aminoglycoside (aztreonam in the setting of renal insufficiency) combined with metronidazole or clindamycin. If an implantable prosthesis is to be used, the AUA recommendations include the preoperative administration of an aminoglycoside (aztreonam in the setting of renal insufficiency) plus a 
first-generation or second-generation cephalosporin or vancomycin. All recommendations include ceasing prophylactic antibiotic administration within $24 \mathrm{~h}$ of surgery.

However, despite clear evidence to show the benefits of antibiotic prophylaxis, lack of compliance is a problem. Timing is particularly important, as administration must occur prior to wound contamination. ${ }^{40-42}$ Antibiotics given more than $2 \mathrm{~h}$ before incision, or any time after incision, are associated with increased rates of surgical site infections. ${ }^{43,44}$ Ideally, antibiotics should be administered $30 \mathrm{~min}$ ( $2 \mathrm{~h}$ for vancomycin) prior to skin incision (and potential contamination) to achieve appropriate therapeutic tissue levels. ${ }^{45}$ A review of total joint arthroplasty operations in The Netherlands confirmed the importance of preincisional prophylactic antibiotics, demonstrating that administration within $30 \mathrm{~min}$ of incision leads to the lowest infection rate. ${ }^{46}$ Similar findings have been demonstrated in developing countries. For example, studies in rural Tanzania demonstrated substantial reductions in surgical site infection rates (from $>20 \%$ to $4 \%$ ) with appropriately selected and timed antibiotic administration. ${ }^{47,48}$ It is also important that prophylactic antibiotics are discontinued within $24 \mathrm{~h}$ of an operation, as prolonged use can lead to bacterial resistance with no demonstrable benefit to the patient. ${ }^{49-52}$ Guidelines recommend that prophylactic antibiotics be initiated $<1 \mathrm{~h}$ prior to incision and stopped $<24 \mathrm{~h}$ after the completion of the operation. ${ }^{53,54}$ Unique to urological surgery is the issue of urinary tract bacterial colonization as a result of indwelling catheters. Although there are no current guidelines regarding the duration of antibiotic use in patients undergoing endoscopic procedures in the setting of chronic urinary drainage, a prudent approach would be to prescribe a culture-directed course of antibiotics immediately prior to the planned procedure.

Preoperative skin preparation is also an important consideration. The use of clippers for hair removal (as opposed to shaving) is an important element of contamination control. This technique has been shown to reduce infection rates and should be considered a standard of care. ${ }^{55-57}$ Although there is no current evidence to show that depilation should be avoided altogether, mechanical hair removal can theoretically cause microabrasions and subsequent bacterial seeding. Data also suggest that a chlorhexidine scrub is superior to a povidone iodine scrub for the decontamination of skin..$^{58}$ Chlorhexidine has a longer timeline of activity and is the standard of care for certain procedures, such as central line insertion. ${ }^{59}$ However, it cannot be used on all body surfaces (such as mucosa of the genitalia), is more expensive than other solutions, and has been associated with an increased risk of fire (owing to the levels of alcohol involved).

\section{Glucose control}

Diabetes is a well-recognized risk factor for morbidity and mortality in surgical patients. In nondiabetic patients, hypergylcaemia is associated with an increased risk of complications $s^{60,61}$ and can be used as a marker of stress and systemic inflammation. It is unclear whether this condition is a cause or manifestation of increased morbidity and mortality. Ever since van den Berghe ${ }^{62}$ published a landmark study of critically ill patients, glycaemic control has been a mantra of perioperative care. ${ }^{62}$ Although initial studies involved cardiac surgery patients, the same principles have been extrapolated to general surgery. In a retrospective study of 995 general and vascular surgery patients, perioperative hyperglycaemia was associated with significantly higher rates of surgical infections and prolonged hospital stay. ${ }^{63}$ However, these findings have not been supported by prospective studies. A study of patients with cardiothoracic conditions randomly assigned to either tight glycaemic control (blood glucose of $80-100 \mathrm{mg} / \mathrm{dl}$ ) using an insulin infusion strategy or conventional treatment (insulin given when blood glucose exceeds $180 \mathrm{mg} / \mathrm{dl}$ ) showed no difference between these groups in terms of postoperative events. Primary combined outcomesincorporating death, sternal infection, prolonged ventilation, cardiac arrhythmias, stroke, and renal failure within 30 days of surgery-occurred in $44 \%$ of patients in the intervention group compared with $46 \%$ of controls. ${ }^{64}$ A Cochrane analysis of perioperative glycaemic control studies failed to find a benefit to stringent glucose control below a threshold of $200 \mathrm{mg} / \mathrm{dl} .^{65}$ However, more recent data suggest that blood glucose levels $>150 \mathrm{mg} / \mathrm{dl}$ are associated with an increased risk of infection of up to $40 \%,{ }^{66}$ supporting targeted glycaemic control aimed at maintaining a perioperative blood glucose of $<150 \mathrm{mg} / \mathrm{dl}$.

The primary concern with tight control of blood glucose levels is the potential for hypoglycaemia, which significantly increases the risk of death. ${ }^{67}$ However, with appropriate safeguards, the benefits of preventing and controlling hyperglycaemia have outweighed the risk of hypoglycaemia and glycaemic control below $200 \mathrm{mg} / \mathrm{dl}$ is the accepted standard of care. ${ }^{68,69}$ The anaesthetist is usually responsible for the maintenance of intraoperative normoglycaemia. In high-risk patients, such as those with diabetes or on steroids, intraoperative glycaemic control is likely to be beneficial and is unlikely to cause harm if carefully performed and blood glucose is regularly evaluated to prevent hypoglycaemia. Further studies are needed to assess whether intraoperative control of hyperglycaemia improves surgical outcomes.

\section{Temperature control}

Hypothermia can cause severe disturbances in homeostasis and predispose patients to bleeding and infection. Enzymatic reactions are not efficient, protein interactions are altered, and the risk of coagulopathy is increased. Under general anaesthesia or deep sedation, intrinsic regulatory mechanisms such as peripheral vasoconstriction or the ability to shiver are subverted. Compounding this is the intense, but often unrecognized, evaporative heat loss of an open cavity such as the chest or abdomen, and the radiant heat loss during times of bleeding and fluid resuscitation. In particular circumstances, such as cardiac arrest for bypass operations, hypothermia is an important component 
of the operative process. For most abdominal, thoracic (excluding cardiac), orthopaedic, gynaecologic, and urologic operations, on the other hand, prevention of hypothermia should be actively pursued. In a multicentre trial in Europe, patients undergoing colectomy had a reduced rate of infection when normothermia was maintained during the operation..$^{70} \mathrm{~A}$ separate trial in the UK of shorter breast, hernia, and varicose vein operations demonstrated a reduction in infection rates when patients were warmed before the operation. ${ }^{71}$ Perioperative cardiac events can also be reduced by maintaining normothermia during major operations. ${ }^{72}$

A number of methods for maintaining normothermia are available. Ambient control involves keeping the patient warm by elevating the room temperature and placing heating devices on exposed parts of the body, such as the extremities, head, or back (between the patient and the bed). The use of warmed intravenous fluids prevents active cooling and frequently increases temperature, particularly in the setting of large-volume blood or crystalloid resuscitations or long procedures. Similarly, warm irrigation should be used when washing out body cavities or operative wounds. For endoscopic transurethral operations, ureteroscopies, and percutaneous renal operations, warm irrigation fluid should be used. For patients who present with hypothermia or become hypothermic, several active techniques can rapidly raise body temperature. These include warm peritoneal or bladder lavage, the use of intravascular heating devices, and even extracorporeal blood warming. ${ }^{73}$

\section{Supplemental oxygen regulation}

The perioperative administration of high concentrations of oxygen has been the subject of a number of studies, but results are inconsistent. ${ }^{74-79}$ The provision of oxygen in this context is thought to increase free radical formation. Polymorphoneuclear leukocytes amass in surgical wounds and are predominantly responsible for the oxidative destruction of pathogens. Thus, the provision of high oxygen tension in tissues and the surgical wound during the perioperative period could help to prevent surgical infections. In colorectal patients, preoperative administration of high levels of inspired oxygen is demonstrably beneficial. An Austrian study randomly assigned 500 patients undergoing colorectal resection to receive either $30 \%$ inspired oxygen (or fraction of inspired oxygen [ $\mathrm{FiO} 2]$ of 0.30 ) or $80 \%$ inspired oxygen $(\mathrm{FiO} 2$ of 0.80 ) during the operation and for $2 \mathrm{~h}$ afterwards. Patients in the $80 \%$ inspired oxygen group exhibited a significant increase in the subcutaneous partial pressure of oxygen and a significantly decreased wound infection rate $(5.2 \%$ versus $11.2 \% ; P=0.01) .{ }^{80} \mathrm{~A}$ double-blinded Spanish study of 300 patients undergoing open colorectal resection from 14 hospitals randomly assigned to receive an $\mathrm{FiO} 2$ of either 0.3 or 0.8 demonstrated that the infection rate was almost $40 \%$ lower in the latter group. ${ }^{81}$

Similar trials have been performed for a number of other surgical procedures, but these have not been as conclusive. In a study of 165 patients undergoing major intra-abdominal surgical procedures under general anaesthesia, patients were randomly assigned to receive an $\mathrm{FiO} 2$ of either 0.80 or 0.35 during surgery and for the first $2 \mathrm{~h}$ postoperatively. Although this trial failed to show a difference in surgical site infection rates, the higher $\mathrm{FiO} 2$ was, in fact, associated with a higher rate of wound complications..$^{82} \mathrm{~A}$ randomized blinded study of obstetric patients undergoing caesarean section was terminated prematurely, owing to a lack of clear benefit during the first interim analysis. ${ }^{83}$ Although comparisons between trials are confounded by the heterogeneity of patients and diagnostic modalities, a meta-analysis published in 2009 concluded that supplemental oxygenation during the perioperative period confers significant protection against infection.$^{84}$ Although efficacy is uncertain in most surgical patients, hyperoxygenation seems to be beneficial in patients undergoing colorectal surgery. Given the similarities, it seems reasonable to extrapolate these findings to patients undergoing cystectomy and urinary diversion procedures. Other types of surgical patients might also benefit from this therapy, which is unlikely to cause ill effects.

\section{B blockade}

B blockade has been well studied in patients with cardiac risk factors (such as known coronary artery disease, hypertension, and diabetes) and clearly shown to reduce deaths following surgery ${ }^{85-88}$ In an assessment of almost 800,000 patients, those with the highest cardiac risk demonstrated the greatest benefit for perioperative $\beta$ blockade, with a relative mortality risk reduction of nearly $50 \% .{ }^{87}$ Although this study was limited by its retrospective methodology and its reliance on claims data, it provided substantial support for the use of $\beta$ blockade during the perioperative period for patients with diabetes, ischaemic heart disease, renal insufficiency, or cerebrovascular disease undergoing thoracic, abdominal, or central vascular operations. Patients taking $\beta$ blockers to treat hypertension or prevent cardiac events demonstrate upregulation of adrenergic receptors, and withdrawal of $\beta$ blockade has been associated with increased cardiac events (even in nonsurgical patients). ${ }^{89-91}$ Preoperative $\beta$ blockade has had mixed effects in patients without cardiac disease or risk factors, and patients who are given a $\beta$ blocker without a clear indication tend to experience worse outcomes. ${ }^{92}$ For patients who are at risk of cardiac events owing to underlying cardiovascular disease, the initiation of $\beta$ blocker therapy can reduce cardiac morbidity and mortality, although the Perioperative Ischemic Evaluation (POISE) trial ${ }^{93}$ reported an increased risk of noncardiac events such as stroke.

The POISE trial was the largest of its kind to examine $\beta$ blockade in a randomized fashion. In this multinational, multicentre, placebo-controlled trial, 8,351 patients with, or at risk of, atherosclerotic disease undergoing noncardiac surgery were randomly assigned to receive either extended-release metoprolol $(100 \mathrm{mg})$ or placebo, preoperatively. Although the primary combined end points of cardiovascular death, nonfatal myocardial infarction, and nonfatal cardiac arrest demonstrated 
improvements with $\beta$ blockade, the final analysis demonstrated an increased mortality risk of $30 \%$. Critics of the study have remarked that the dosage used was excessive and that patients at the highest risk of cardiac death were poorly identified. By comparison, other investigators have noted that low-dose $\beta$ blockade is safe, effective, and not associated with an increased incidence of stroke in intermediate-risk patients. ${ }^{94}$ However, POISE was well controlled and likely to be reflective of general practice patterns. Thus, until further evidence indicates otherwise, patients without clear indications for $\beta$ blockade (who are not already taking it preoperatively) should not initiate treatment prior to elective surgery.

\section{Venous thromboembolism prophylaxis}

The risk of venous thromboembolism (VTE) varies dramatically, depending on the type of operation and the patient risk factors. Immobility, hypercoagulability, cancer, and long-bone fractures, along with prolonged operations and abdominal and orthopaedic procedures, all increase the risk of developing VTE. Without thromboprophylaxis, the estimated risk of developing a deep venous clot ranges from $<0.5 \%$ for most low-risk outpatient procedures or same-day operations to $6 \%$ for operations for trauma and oncologic conditions, or in high-risk patients, including those aged $>70$ years or in hypercoaguable states. ${ }^{95}$ Three primary strategies exist to prevent VTE in surgical patients: mechanical devices (such as graded compression stockings and intermittent pneumatic compression boots), pharmacologic therapies (including subcutaneous injections of unfractionated heparin and low molecular weight heparins), and early ambulation. Thrombosis associated with surgery usually originates intraoperatively in the deep calf veins, although many thrombi resolve spontaneously within 3 days. ${ }^{96}$ During surgery, mechanical devices are generally considered to be low risk and these tools - which prevent venous thrombosis by promoting venous blood flow and stimulating endogenous fibrinolytic activity, mediated by the stimulation of tissue plasminogen activity and reduction of plasminogen activator inhibitor-1-are deployed as standard in the inpatient setting. ${ }^{97}$ For short cases and in the outpatient setting, their use is more variable and is often determined by cost, as their effect is likely to be minimal in these environments. ${ }^{98}$

Recommendations regarding the perioperative use of subcutaneous anticoagulants are less clear cut, as risk stratification requires consideration of both the patient and procedural risk factors. ${ }^{95}$ The risk of bleeding must be weighed against the risks of thrombosis, and much depends on this assessment by the surgical team. VTE risk factors for surgical patients include the type of surgical procedure, smoking, cancer, hypercoaguable state, prior history of VTE or pulmonary embolism, trauma, immobility, pregnancy, and other hyperoestrogen states, such as oral contraception and hormone replacement therapy ${ }^{99}$ Certain procedures, such as orthopaedic operations involving joint replacement or fracture reduction, are fraught with risk and perioperative pharmacologic prophylaxis should be routine (provided contraindications are not present). For other types of procedures, calculating the risk of VTE tends to be less straightforward, particularly for low-risk patients undergoing intermediate-risk operations such as nononcologic open or laparoscopic abdominopelvic surgery. Concerns are amplified when intraoperative or postoperative bleeding is considered likely or potentially catastrophic.

Several organizations, including the American College of Chest Physicians, the French Society of Anaesthesiology and Intensive Care, and the AUA, have published guidelines for VTE prophylaxis. ${ }^{95,99-101}$ These published guidelines recommend treatment gradation based on patient risk factors, the procedure, and the risk of postoperative VTE. High-risk operations almost always require some form of chemical VTE prophylaxis, whereas low-risk urological operations (particularly those performed in the outpatient setting) and short endoscopy procedures do not generally require such measures in the absence of other risk factors. In such situations, other interventions can be more beneficial and cost effective; for example, the urologic literature supports the use of calf-length intermittent pneumatic compression boots instead of full-length compression boots, as these provide equivalent outcomes and the calf length devices are less expensive. ${ }^{102}$ Time-consuming invasive cancer operations are associated with a substantial risk of VTE, and both mechanical and chemical prophylaxis should be considered. ${ }^{103}$ If VTE prophylaxis is to be implemented, mechanisms to ensure its appropriate use-such as confirming sequential compression machines are turned on and pharmacologic prophylaxis is given at the appropriate time-are self-evident.

\section{Measuring safety}

Quality assessments are essential for improving the quality of surgical care. Surveillance systems that evaluate surgical site infections have been shown to reduce rates of infectious complications when they are incorporated into a system that provides feedback to individual surgeons and departments. ${ }^{104-107}$ When surgeon-specific feedback systems were used in South America, Europe, and the USA, surgical site infection rates were consistently reduced by over a third-and sometimes by more than half-when combined with organized surveillance and control, education, and standardization of infection control policies. ${ }^{108-113}$ Some of these studies were performed over $>2$ years, indicating durability and sustainability. Other outcomes, such as morbidity and mortality, can be more complex to evaluate after discharge from the hospital and often involve data collection mechanisms that are expensive and time-consuming to institute. Of these parameters, perioperative mortality is a welldefined end point that has been introduced across the UK. ${ }^{114,115}$ Other sophisticated, risk-adjusted complication and mortality reporting systems have been implemented in Canada, Europe, and the USA. These measurement systems can be specific to particular specialties, such as cardiac surgery, or universal (for example, the United States Veterans Health System). ${ }^{116-121}$ 
Large databases and registries provide information regarding the quality and outcomes of care. In the USA, the National Surgical Quality Improvement Program (NSQIP) administered by the ACS uses patient medical record data to help surgeons and departments to benchmark themselves against their peers and provide insight into complication and death rates in a risk-adjusted fashion. ${ }^{122}$ This database contains data for general and vascular surgical patients at hospitals that participate in the NSQIP and enables surgeons to identify problems and deficiencies within their department and promote process improvements to address these issues. ${ }^{123}$ Trauma and cancer registries constitute two other prominent databases that provide metrics to enable facility-level comparisons of treatment modalities and systems of care. Trauma system efficacy has been evaluated at both national and international levels, ${ }^{124-126}$ guiding recommendations for improvements in infrastructure, planning, training, and care. ${ }^{127-131}$ In addition to confirming the positive association between higher surgical volumes and improved outcomes, ${ }^{132-134}$ data from cancer registries have helped to refine the timing and extent of surgical resections for a variety of malignancies and led to changes in the use of perioperative neoadjuvant chemoradiation and the organization of care systems towards a multidisciplinary approach. ${ }^{135-139}$

Safety evaluations also rely on regional and statebased collaborative programs, such as the Washington State Surgical Care and Outcomes Assessment Program (SCOAP). ${ }^{140}$ This program is modelled on methodologies used by the aviation industry to ensure safety. It uses a surveillance and response system that identifies variations in the processes and outcomes reported by hospitals within the state and reports those variations back to individual hospitals and departments in an attempt to improve quality. Through multihospital collaboration, SCOAP has developed its own evaluation metrics, as well as customized interventions-including a modification of the WHO Surgical Safety Checklist-to ensure safer, more cost-effective surgical care. ${ }^{141}$ An added advantage of SCOAP is that surgical initiatives are flexible, clinically relevant, timely, and can be rapidly implemented throughout the state. ${ }^{142}$

A strategic mechanism for assessing the safety of surgical care relies on standardized information collected in a structured manner. Such measurement modalities are vital for ensuring that the quality of care is improved and that resources are allocated in an effective, evidencebased manner. The WHO has highlighted the importance of measuring surgical services and advocated the reporting and assessment of service delivery and outcomes (Box 2) ${ }^{54,143}$ More importantly for individual providers, a strategic outcomes-based assessment of individual, departmental, and hospital surgical data could highlight safety lapses and identify areas for improvement and systemization of care.

\section{Training, specialization, and systematization}

The length, intensity, and structure of training have always been subject to intense debate. No single system of
Box $2 \mid$ Proposed metrics for evaluating the safety and delivery of surgical care ${ }^{143}$

- Number of operating rooms

- Numbers of accredited surgeons and anaesthesia professionals

- Number of surgical procedures done in an operating room per year

- Day-of-surgery death ratio-number of deaths on the day of surgery divided by the number of surgical procedures performed in a given year or period (\%)

- Postoperative in-hospital death ratio-number of deaths in the hospital following surgery (irrespective of cause and limited to 30 days) divided by the number of surgical procedures performed in a given year or period (\%)

surgical training has answered the fundamental question of how best to impart skills to surgical trainees. Although the $10,000 \mathrm{~h}$ theory for achieving mastery is a potential explanation (discussed by Malcolm Gladwell in his book entitled 'Outliers'), further studies have sought to determine whether simulation can augment, or even serve as a substitute for, traditional training paradigms. ${ }^{144,145}$ The concept of deliberate practice-the process of immediate feedback, structured drills, and repetition-is likely the mechanism by which surgical skills are best transferred to novices. ${ }^{146,147}$ This model suggests that training paradigms that capitalize on these practices would provide the best technical experiences for trainees. Further work is now ongoing regarding the ability to provide structured feedback on performance improvement to practicing surgeons through expert coaching. ${ }^{148}$ Surgical simulators have the potential to expose trainees to the basic skills that are required to master surgical techniques before they enter the operating room. For example, surgical simulation training is being used for both adult and paediatric urologic procedures. ${ }^{149,150}$

As the complexity of surgical practice has grown, there has been an increasing trend towards specialization by both practitioners and hospitals. The past 30 years has seen increasing subspecialization, manifested by dramatic growth of fellowships and centres of excellence. This growth has been driven by increased complexity in both patient conditions and therapeutic options and also by strong data supporting the positive correlation between surgical volume and outcomes, which is particularly evident for specific, complex procedures such as oesophagectomy, pancreaticoduodenectomy, nephrectomy, and cystectomy. ${ }^{7}$ Similar studies support systems created to treat acutely unstable, traumatized patients. Outcomes at these specialist centres far exceed those of nonspecialist centres that treat complex trauma. ${ }^{131}$ In addition, improvements in care have been linked to the concept of 'failure to rescue', whereby complication rates across hospitals are deemed to be similar but some hospitals are more able to identify and support patients with complications, leading to lower mortality and morbidity rates. ${ }^{151}$ However, certain features and characteristics of hospitals can be correlated with ability to provide highquality outcomes regardless of surgical volume, suggesting that the system itself can help mitigate harm and provide the complex care necessary to support critically ill patients through recovery. ${ }^{152,153}$ This finding suggests that the technical skills of the surgical team, strong teamwork dynamics, and robust perioperative patient care 


\section{Surgical Safety Checklist}

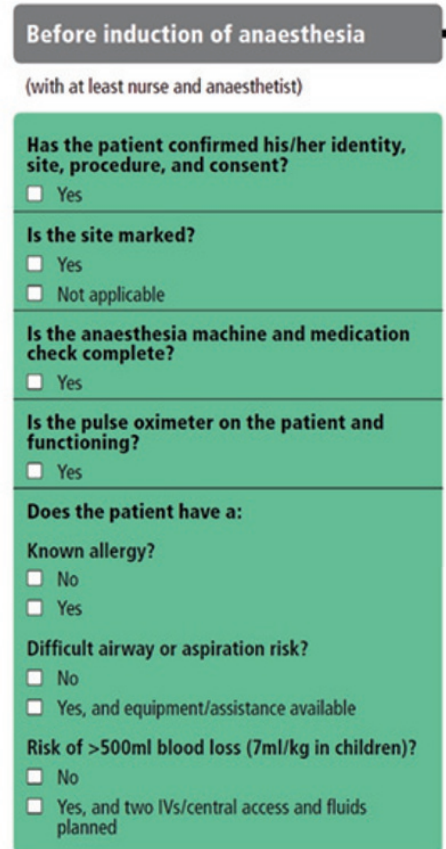

This checklist is not intended to be comprehensive. Additions and modifications to fit local practice are encouraged.

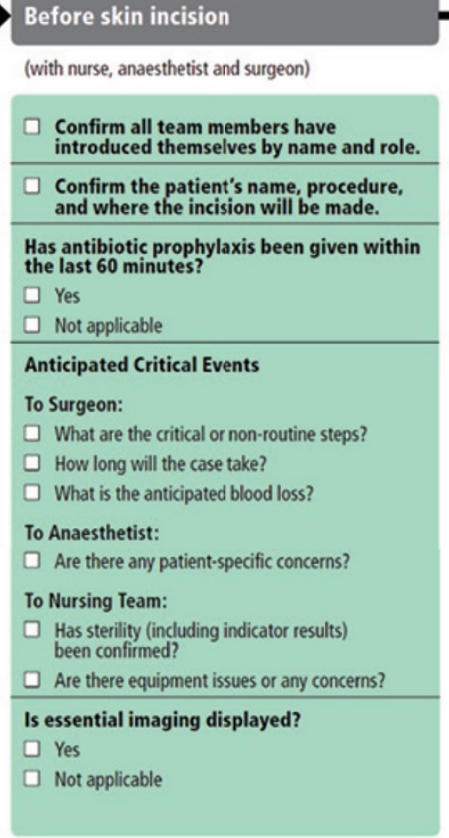

\begin{tabular}{|c|c|}
\hline$\square$ & $\begin{array}{l}\text { Confirm all team members have } \\
\text { introduced themselves by name and role. }\end{array}$ \\
\hline$\square$ & $\begin{array}{l}\text { Confirm the patient's name, procedure, } \\
\text { and where the incision will be made. }\end{array}$ \\
\hline \multicolumn{2}{|r|}{$\begin{array}{l}\text { Has antibiotic prophylaxis been given within } \\
\text { the last } 60 \text { minutes? }\end{array}$} \\
\hline$\square$ & Yes \\
\hline & Not applicable \\
\hline \multicolumn{2}{|r|}{ Anticipated Critical Events } \\
\hline \multicolumn{2}{|c|}{ To Surgeon: } \\
\hline$\square$ & What are the critical or non-routine steps? \\
\hline$\square$ & How long will the case take? \\
\hline$\square$ & What is the anticipated blood loss? \\
\hline \multicolumn{2}{|c|}{ To Anaesthetist: } \\
\hline$\square$ & Are there any patient-specific concerns? \\
\hline \multicolumn{2}{|c|}{ To Nursing Team: } \\
\hline & $\begin{array}{l}\text { Has sterility (including indicator results) } \\
\text { been confirmed? }\end{array}$ \\
\hline$\square$ & Are there equipment issues or any concerns? \\
\hline \multicolumn{2}{|r|}{ Is essential imaging displayed? } \\
\hline$\square$ & Yes \\
\hline & Not applicable \\
\hline
\end{tabular}

Figure 4 | The WHO Surgical Safety Checklist was tested in eight hospitals in eight different countries, representing both resource-rich and resource-poor populations. This 19-item safety tool has helped to improve clinician compliance with accepted standards of perioperative care, resulting in significantly reduced rates of complications and postoperative mortality ( $36 \%$ and $47 \%$, respectively). Permissions to reproduce received from the WHO. ${ }^{168}$

processes are the true qualities needed for improving performance and surgical outcomes.

\section{Checklists, care bundles, and training}

The success of every operation requires the perfect orchestration of highly complex tasks. The combination of complex patient characteristics, therapeutic options, technical demands, and team dynamics create a situation that is difficult to standardize. That said, specific interventions can help to align the human factors responsible for achieving improved performance. In 2009, the WHO published the results of a multicentre trial assessing the efficacy of a perioperative surgical safety checklist on morbidity and mortality (Figure 4). In an analysis of nearly 8,000 surgical patients, this 19 -item checklist was shown to improve adherence to basic standards of care, reduce the number of deaths by more than $30 \%$, and cut complication rates nearly in half. ${ }^{154}$ The investigators reported a twofold increase in compliance with six measured safety steps: objective airway evaluation, confirmation of procedure and operative site, preoperative administration of antibiotics, adequate intravenous access when blood loss exceeds $500 \mathrm{ml}$, use of pulse oximetry throughout the anesthetic, and completion of sponge and instrument counts. The benefits of using this checklist extended to urgent and emergency surgery cases. ${ }^{155}$ However, one stated weakness of this study was its preinterventional versus postinterventional design, which lacked a standalone control group and predisposed the measuring of processes and outcomes to a strong Hawthorne effect (the observation that results improve when they are under investigation). In addition, although the six measured items did not account for the magnitude of the Hawthorne effect on patient safety, it is possible that the other safety items, including the team briefing and debriefing, exerted a beneficial effect. However, as these items were not explicitly studied, their impact is merely conjectural.

Since the publication of this study in 2009, several other studies have confirmed the effect of checklists as tools for ensuring the safe conduct of surgery. A large, well-designed study in The Netherlands demonstrated that the implementation of a perioperative checklist at six Dutch hospitals significantly improved rates of mortality compared with five control hospitals. ${ }^{156}$ The intervention reduced total complications by nearly $40 \%$ and mortality by $47 \%$, an effect almost as substantial as that reported in the original WHO study. Another checklist intervention study in over 25,000 patients (14,362 preintervention and 11,151 postintervention) from The Netherlands reported very similar findings to the WHO investigation, demonstrating clear improvements that could be directly attributed to checklist use. ${ }^{157}$ Accordingly, checklists should now be considered a standard of care 
in the perioperative preparation period. ${ }^{158}$ Nevertheless, it is worth noting that the principle function of checklists is not to dictate what clinicians should do, but rather to provide prompts for communicating important information and confirming critical steps before their implementation becomes ineffectual. The utility of checklists has been well studied in the airline industry and has been incorporated into crew resource managementa method of team training (based on shared mental models for care and conduct) that has been implemented in many operating rooms and hospitals. Teamwork is clearly an essential component of care. A large, multicentre Veterans Administration study demonstrated profound improvements in patient outcomes when team training was implemented amongst operating room personnel. ${ }^{159}$ This study established that checklists were a key component for generating and promoting team interaction. Of particular importance is the observation that teams who consistently work together are more efficient (and generate better outcomes) than teams with rotating members. ${ }^{160,161}$ Maintaining this consistency is often difficult, particularly in acute settings or when faced with human-resource constraints. These challenges make checklists all the more important as a means of ensuring consistency in the care process.

Checklists can help improve the use of care bundles, such as those instituted in intensive care units to prevent ventilator-associated pneumonia and central-line bloodstream infections (Figure 5). The problem with evaluating the success of care bundles is that improvements to individual components of care do not always affect outcomes when studied in large databases. Many of the risk-factor-reduction strategies enumerated in this article-from hypothermia prevention to glucose control-are now considered to be markers of quality and might even be tied to financial rewards or reimbursements. However, studies evaluating the effects of these individual quality measures often fail to demonstrate improvements in outcomes, despite high compliance. One study evaluating outcomes in 398 US hospitals reported no improvement in care when these individual safety components were closely adhered to. ${ }^{162}$ However, this study did demonstrate a clear improvement to outcomes when hospitals implemented all components at the same time, suggesting that compliance across multiple quality indicators might be a marker of improved systematization of care. ${ }^{163}$ That said, checklists are not a panacea. When checklists are used merely for auditing or administrative purposes without team investment in the process, they rarely result in improved care. In an observational study of 142 paediatric surgical patients in a single hospital, checklists were incompletely executed for all of these patients, despite a reported $100 \%$ documented completion rate. ${ }^{164}$ This finding was probably the result of poor implementation and dissemination. Checklists are best used to reinforce communication, prompt genuine dialogue and exchanges of critical information, and as part of on ongoing feedback and performance improvement system. ${ }^{165}$ In addition, they should be integrated into the culture of the operating

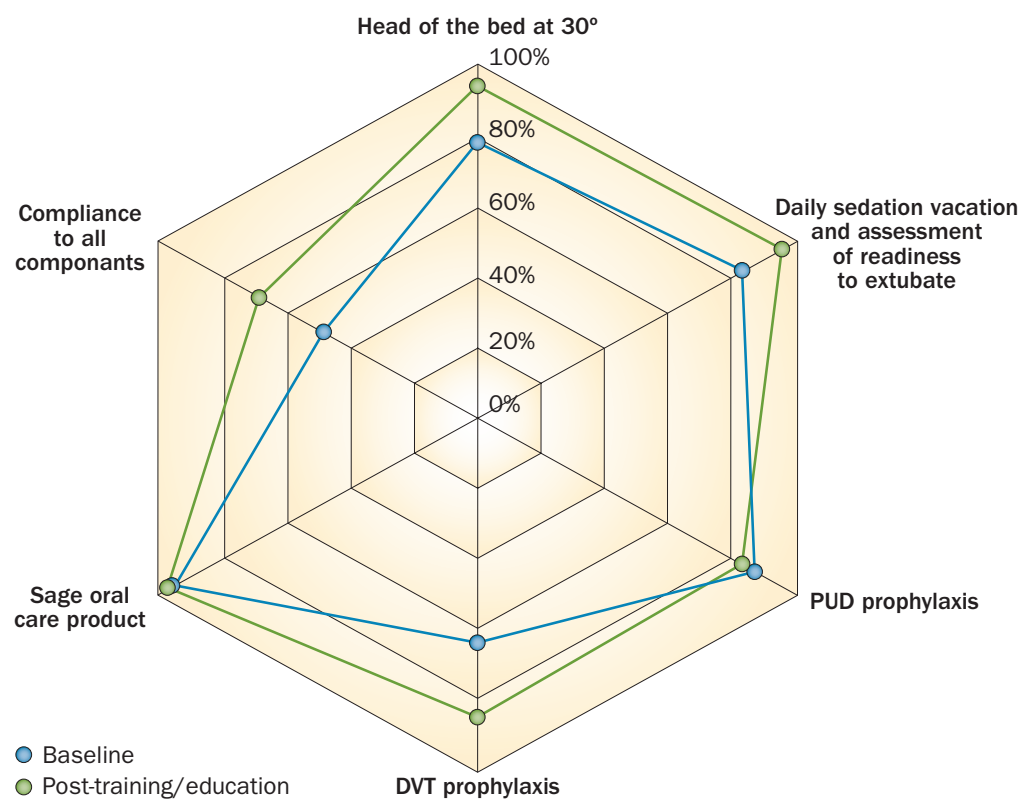

Figure 5 | Spider web diagram demonstrating compliance with a ventilator bundle. This image demonstrates a strategy for visually presenting compliance with multiple elements of care in a single, easily understandable graphic. ${ }^{169}$ Permissions to reproduce obtained from RT magazine. Abbreviations: DVT, deep vein thrombosis; PUD, peptic ulcer disease.

room in a way that is useful, valuable, and supports clinical care, rather than serving as a barrier to efficiency and autonomy.

\section{Conclusions}

Surgical safety is a priority for all surgical clinicians, but the complexity of the tasks involved makes 'perfect' care difficult to define, let alone achieve. Hospitals and health-care systems are increasingly evaluating the system of care delivery and searching for ways to improve coordination, communication, and efficiency. From point-of-care interventions to checklists and team training, the disciplines involved in surgical care are built upon group knowledge and past experience to maximize the likelihood of better outcomes. However, there is still a long way to go. Firstly, it is not entirely clear how to measure quality and safety. Specific measures might demonstrate effects in certain well-controlled circumstances, but these effects are often difficult to reproduce and fail to deliver system-wide results. Secondly, many interventions are temporally distant from their effects, making cause-and-effect linkages difficult to determine. Thirdly, long-term follow-up data can be exceedingly difficult to obtain, but these are fundamental to the accurate measurement of progress. Fourthly, increases in global health-care costs demand greater commitment to quality and a better understanding of how health-care systems can provide cost-effective interventions. In the USA - which is currently struggling under the financial burdens of health care-pay-for-performance initiatives are forcing providers to evaluate their outcomes and determine mechanisms for improving the quality and safety of care. 
The coordination of surgical care requires the complex orchestration of multiple disciplines, from nurses to anaesthetists to surgeons. Ensuring adherence to all appropriate steps of care, while avoiding errors of omission and commission, is just the beginning. Communication between providers is increasingly important in the ever-changing health-care environment. Moreover, a strong commitment to the close evaluation of outcomes of therapy, the process by which patients are treated, and the system by which surgical care is provided is essential. This commitment provides transparency, reassures patients that the care they receive is reviewed continuously, and ensures that improvements are always part of the culture of medicine.

\section{Review criteria}

We performed a search of the English-language literature using PubMed and Google Scholar databases. Keywords used in our search included "surgery", "surgical", "safety", "outcomes", "quality", "team", and "checklist". Publications were selected, in part, on the basis of the reputation of the journal, the quality of the study, and the impact of the results. We also searched the reference lists of articles identified by this search strategy, as well as PubMed prompts of related citations. In addition, we employed our previous knowledge in this field to identify alternative sources, such as textbooks and monographs. Non-Englishlanguage papers were only selected for inclusion if we were familiar with the study, author, and results.
1. Kohn, L. T., Corrigan, J. M. \& Donaldson, M. S. To err is human: building a safer health system (National Acadamy Press, Washington, DC, USA, 1999).

2. Weiser, T. G. et al. In-hospital death following inpatient surgical procedures in the United States, 1996-2006. World J. Surg. 35 1950-1956 (2011).

3. Noordzij, P. G. et al. Postoperative mortality in The Netherlands: a population-based analysis of surgery-specific risk in adults. Anesthesiology 112, 1105-1115 (2010).

4. Pearse, R. M. et al. Mortality after surgery in Europe: a 7 day cohort study. Lancet $\mathbf{3 8 0 ,}$ 1059-1065 (2012).

5. Barbieri, C. E. et al. Association of procedure volume with radical cystectomy outcomes in a nationwide database. J. Urol. 178, 1418-1422 (2007).

6. Konety, B. R., Dhawan, V., Allareddy, V. \& Joslyn, S. A. Impact of hospital and surgeon volume on in-hospital mortality from radical cystectomy: data from the health care utilization project. J. Urol. 173, 1695-1700 (2005).

7. Birkmeyer, J. D. et al. Hospital volume and surgical mortality in the United States. N. Engl. J. Med. 346, 1128-1137 (2002).

8. Gawande, A. A., Thomas, E. J., Zinner, M. J. $\&$ Brennan, T. A. The incidence and nature of surgical adverse events in Colorado and Utah in 1992. Surgery 126, 66-75 (1999).

9. Kable, A. K., Gibberd, R. W. \& Spigelman, A. D. Adverse events in surgical patients in Australia. Int. J. Qual. Health Care 14, 269-276 (2002).

10. Wilson, R. M. et al. Patient safety in developing countries: retrospective estimation of scale and nature of harm to patients in hospital. BMJ $\mathbf{3 4 4}$, e832 (2012).

11. Weiser, T. et al. An estimation of the global volume of surgery: a modelling strategy based on available data. Lancet 372, 139-144 (2008).

12. Rebuck, D. A. et al. Simple modifications in operating room processes to reduce the times and costs associated with robot-assisted laparoscopic radical prostatectomy. J. Endourol. 25, 955-960 (2011).

13. Kenyon, T. A. et al. Dedicated minimally invasive surgery suites increase operating room efficiency. Surg. Endosc. 15, 1140-1143 (2001).

14. Hsiao, K. C., Machaidze, Z. \& Pattaras, J. G. Time management in the operating room: an analysis of the dedicated minimally invasive surgery suite. JSLS 8, 300-303 (2004).

15. van Det, M. J., Meijerink, W. J., Hoff, C. \& Pierie, J. P. Interoperative efficiency in minimally invasive surgery suites. Surg. Endosc. 23, 2332-2337 (2009).
16. Accreditation Council for Graduate Medical Education (ACGME). ACGME competencies: Common program requirement [online], http:// www.acgme.org/acgmeweb/Portals/O/PDFs/ commonguide/IVA5f EducationalProgram ACGMECompetencies_SBP_Explanation.pdf (2012).

17. Eichhorn, J. H. et al. Standards for patient monitoring during anesthesia at Harvard Medical School. JAMA 256, 1017-1020 (1986).

18. International Task Force on Anaesthesia Safety. International standards for a safe practice of anaesthesia. Eur. J. Anaesthesiol. 10 (Suppl. 7), 12-15 (1993).

19. Pierce, E. C. The 34th Rovenstine Lecture: 40 years behind the mask - safety revisited. Anesthesiology 84, 965-975 (1996).

20. Bainbridge, D., Martin, J., Arango, M. \& Cheng, D. Perioperative and anaesthetic-related mortality in developed and developing countries: a systematic review and meta-analysis. Lancet 380, 1075-1081 (2012).

21. Walker, I. A. \& Wilson, I. H. Anaesthesia in developing countries - a risk for patients. Lancet 371, 968-969 (2008).

22. Wilson, I. H. \& Walker, I. A. Lifebox: give a little, help a lot. BMJ 344, e313 (2012).

23. Lifebox. Saving lives through safer surgery [online], http://www.lifebox.org (2012).

24. Klevens, R. M. et al. Estimating health care-associated infections and deaths in U.S. hospitals, 2002. Public Health Rep. 122 , 160-166 (2007).

25. Coello, R. et al. Adverse impact of surgical site infections in English hospitals. J. Hosp. Infect. 60, 93-103 (2005).

26. National Nosocomial Infections Surveillance (NNIS) System. National Nosocomial Infections Surveillance (NNIS) System Report, data summary from January through June 2004, issued October 2004. Am. J. Infect. Control 32, 470-485 (2004).

27. Jodra, V. M. et al. Results of the Spanish national nosocomial infection surveillance network (VICONOS) for surgery patients from January through December 2003. Am. J. Infect. Control 34, 134-141 (2006).

28. Leaper, D. J. et al. Surgical site infection-a European perspective of incidence and economic burden. Int. Wound J. 1, 247-273 (2004).

29. Kirkland, K. B., Briggs, J. P., Trivette, S. L., Wilkinson, W. E. \& Sexton, D. J. The impact of surgical-site infections in the 1990s: attributable mortality, excess length of hospitalization, and extra costs. Infect. Control Hosp. Epidemiol. 20, 725-730 (1999).
30. Jenney, A. W., Harrington, G. A., Russo, P. L. \& Spelman, D. W. Cost of surgical site infections following coronary artery bypass surgery. ANZ J. Surg. 71, 662-664 (2001).

31. Reilly, J., Allardice, G., Bruce, J., Hill, R. \& McCoubrey, J. Procedure-specific surgical site infection rates and postdischarge surveillance in Scotland. Infect. Control Hosp. Epidemiol. 27 1318-1323 (2006).

32. Broex, E. C., van Asselt, A. D., Bruggeman, C. A. \& van Tiel, F. H. Surgical site infections: how high are the costs? J. Hosp. Infect. 72, 193-201 (2009).

33. Urban, J. A. Cost analysis of surgical site infections. Surg. Infect. 7 (Suppl. 1), S19-S22 (2006).

34. Fry, D. E. The economic costs of surgical site infection. Surg. Infect. 3 (Suppl. 1), S37-S43 (2002).

35. de Lissovoy, G. et al. Surgical site infection: incidence and impact on hospital utilization and treatment costs. Am. J. Infect. Control 37, 387-397 (2009).

36. Dellinger, E. P. et al. Quality standard for antimicrobial prophylaxis in surgical procedures. Infectious Diseases Society of America. Clin. Infect. Dis. 18, 422-427 (1994).

37. Page, C. P. et al. Antimicrobial prophylaxis for surgical wounds: Guidelines for clinical care. Arch. Surg. 128, 79-88 (1993).

38. Platt, R. et al. Perioperative antibiotic prophylaxis for herniorrhaphy and breast surgery. N. Engl. J. Med. 322, 153-160 (1990).

39. American Urological Association (AUA). Best Practice Policy Statement on Urologic Surgery Antimicrobial Prophylaxis [online], http://www.auanet.org/content/media/ antimicroprop08.pdf (2007).

40. Burke, J. F. \& Miles, A. A. The sequence of vascular events in early infective inflammation. J. Pathol. Bacteriol. 76, 1-19 (1958).

41. Burke, J. F. The effective period of preventive antibiotic action in experimental incisions and dermal lesions. Surgery 50, 161-168 (1961).

42. Dellinger, E. P. Prophylactic antibiotics: administration and timing before operation are more important than administration after operation. Clin. Infect. Dis. 44, 928-930 (2007)

43. Stone, H. H., Hooper, C. A., Kolb, L. D., Geheber, C. E. \& Dawkins, E. J. Antibiotic prophylaxis in gastric, biliary and colonic surgery. Ann. Surg. 184, 443-452 (1976).

44. Classen, D. C. et al. The timing of prophylactic administration of antibiotics and the risk of surgical-wound infection [see comments]. N. Engl. J. Med. 326, 281-286 (1992). 
45. DiPiro, J. T. et al. Intraoperative serum and tissue activity of cefazolin and cefoxitin. Arch. Surg. 120, 829-832 (1985).

46. van Kasteren, M. E. et al. Antibiotic prophylaxis and the risk of surgical site infections following total hip arthroplasty: timely administration is the most important factor. Clin. Infect. Dis. $\mathbf{4 4}$ 921-927 (2007).

47. Saxer, F. et al. Benefit of a single preoperative dose of antibiotics in a sub-saharan district hospital: minimal input, massive impact. Ann. Surg. 249, 322-326 (2009).

48. Fehr, J. et al. Antimicrobial prophylaxis to prevent surgical site infections in a rural subSaharan hospital. Clin. Microbiol. Infect. 12 1224-1227 (2006).

49. Bucknell, S. J., Mohajeri, M., Low, J., McDonald, M. \& Hill, D. G. Single-versus multiple-dose antibiotics prophylaxis for cardiac surgery. Aust. NZ J. Surg. 70, 409-411 (2000).

50. McDonald, M., Grabsch, E., Marshall, C. \& Forbes, A. Single- versus multiple-dose antimicrobial prophylaxis for major surgery: a systematic review. Aust. NZ J. Surg. 68, 388-396 (1998)

51. Kriaras, I. et al. Antibiotic prophylaxis in cardiac surgery. J. Cardiovasc. Surg. 38, 605-610 (1997).

52. Harbarth, S., Samore, M. H., Lichtenberg, D. \& Carmeli, Y. Prolonged antibiotic prophylaxis after cardiovascular surgery and its effect on surgical site infections and antimicrobial resistance. Circulation 101, 2916-2921 (2000).

53. Bratzler, D. W. \& Houck, P. M. Antimicrobial prophylaxis for surgery: an advisory statement from the National Surgical Infection Prevention Project. Clin. Infect. Dis. 38, 1706-1715 (2004).

54. World Health Organization (WHO). WHO Guidelines for Safe Surgery (WHO, Geneva, 2009).

55. Mangram, A. J., Horan, T. C., Pearson, M. L., Silver, L. C. \& Jarvis, W. R. Guideline for prevention of surgical site infection, Hospital Infection Control Practices Advisory Committee. Infect. Control Hosp. Epidemiol. 20, 250-280 (1999).

56. Kjonniksen, I., Andersen, B. M., Sondenaa, V. G. \& Segadal, L. Preoperative hair removal-a systematic literature review. AORN J. 75, 928-940 (2002).

57. Tanner, J., Norrie, P. \& Melen, K. Preoperative hair removal to reduce surgical site infection. Cochrane Database Syst. Rev. Issue 11. Art. No.: CD004122. doi:10.1002/ 14651858.CD004122.pub4 (2011).

58. Darouiche, R. O. et al. Chlorhexidine-alcoho versus povidone-iodine for surgical-site antisepsis. N. Engl. J. Med. 362, 18-26 (2010).

59. Pronovost, P. et al. An intervention to decrease catheter-related bloodstream infections in the I.C.U. N. Engl. J. Med. 355, 2725-2732 (2006).

60. Latham, R., Lancaster, A. D., Covington, J. F., Pirolo, J. S. \& Thomas, C. S. The association of diabetes and glucose control with surgical-site infections among cardiothoracic surgery patients. Infect. Control Hosp. Epidemiol. 22, 607-612 (2001).

61. Pomposelli, J. J. et al. Early postoperative glucose control predicts nosocomial infection rate in diabetic patients. JPEN J. 22, 77-81 (1998).

62. van den Berghe, G. et al. Intensive insulin therapy in the surgical intensive care unit. N. Engl. J. Med. 345, 1359-1367 (2001).

63. Ramos, M. et al. Relationship of perioperative hyperglycemia and postoperative infections in patients who undergo general and vascular surgery. Ann. Surg. 248, 585-591 (2008).
64. Gandhi, G. Y. et al. Intensive intraoperative insulin therapy versus conventional glucose management during cardiac surgery: a randomized trial. Ann. Intern. Med. 146, 233-243 (2007).

65. Kao, L. S., Meeks, D., Moyer, V. A. \& Lally, K. P. Peri-operative glycaemic control regimens for preventing surgical site infections in adults. Cochrane Database Syst. Rev. Issue 3. Art. No.: CD006806. doi: 10.1002/ 14651858.CD006806.pub2 (2009)

66. King, J. T., Goulet, J. L. Jr, Perkal, M. F. \& Rosenthal, R. A. Glycemic control and infections in patients with diabetes undergoing noncardiac surgery. Ann. Surg. 253, 158-165 (2011).

67. Finfer, S. et al. Hypoglycemia and risk of death in critically ill patients. N. Engl. J. Med. 367 1108-1118 (2012)

68. Dellinger, E. P. Preventing surgical-site infections: the importance of timing and glucose control. Infect. Control Hosp. Epidemiol. 22, 604-606 (2001).

69. Garber, A. J. et al. American College of Endocrinology position statement on inpatient diabetes and metabolic control. Endocr. Pract. 10 (Suppl. 2), 4-9 (2004).

70. Kurz, A., Sessler, D. I. \& Lenhardt, R. Perioperative normothermia to reduce the incidence of surgical-wound infection and shorten hospitalization. Study of Wound Infection and Temperature Group [see comments]. N. Engl. J. Med. 334, 1209-1215 (1996).

71. Melling, A. C., Ali, B., Scott, E. M. \& Leaper, D. J. Effects of preoperative warming on the incidence of wound infection after clean surgery: a randomised controlled trial. Lancet 358, 876-880 (2001)

72. Frank, S. M. et al. Perioperative maintenance of normothermia reduces the incidence of morbid cardiac events. A randomized clinical trial. JAMA 277, 1127-1134 (1997).

73. Gregory, J. S., Bergstein, J. M., Aprahamian, C., Wittmann, D. H. \& Quebbeman, E. J. Comparison of three methods of rewarming from hypothermia: advantages of extracorporeal blood warming. J. Trauma 31, 1247-1252 (1991).

74. Hunt, T. K., Linsey, M., Grislis, H., Sonne, M. \& Jawetz, E. The effect of differing ambient oxygen tensions on wound infection. Ann. Surg. 181, 35-39 (1975).

75. Hohn, D. C., MacKay, R. D., Halliday, B. \& Hunt, T. K. Effect of $\mathrm{O} 2$ tension on microbicidal function of leukocytes in wounds and in vitro. Surg. Forum 27, 18-20 (1976).

76. Hopf, H. W. et al. Wound tissue oxygen tension predicts the risk of wound infection in surgical patients. Arch. Surg. 132, 997-1005 (1997).

77. Knighton, D. R. et al. Oxygen as an antibiotic. The effect of inspired oxygen on bacterial clearance. Arch. Surg. 125, 97-100 (1990).

78. Knighton, D. R., Halliday, B. \& Hunt, T. K. Oxygen as an antibiotic. The effect of inspired oxygen on infection. Arch. Surg. 119, 199-204 (1984).

79. Knighton, D. R., Halliday, B. \& Hunt, T. K. Oxygen as an antibiotic. A comparison of the effects of inspired oxygen concentration and antibiotic administration on in vivo bacterial clearance. Arch. Surg. 121, 191-195 (1986)

80. Greif, R., Akca, O., Horn, E. P., Kurz, A. \& Sessler, D. I. Supplemental perioperative oxygen to reduce the incidence of surgicalwound infection. Outcomes Research Group [see comments]. N. Engl. J. Med. 342, 161-167 (2000).

81. Belda, F. J. et al. Supplemental perioperative oxygen and the risk of surgical wound infection: a randomized controlled trial. JAMA 294, 2035-2042 (2005).

82. Pryor, K. O., Fahey, T. J., Lien, C. A. \& Goldstein, P. A. Surgical site infection and the routine use of perioperative hyperoxia in a general surgical population: a randomized controlled trial. JAMA 291, 79-87 (2004).

83. Gardella, C. et al. High-concentration supplemental perioperative oxygen to reduce the incidence of postcesarean surgical site infection: a randomized controlled trial. Obstet. Gynecol. 112, 545-552 (2008).

84. Qadan, M., Akca, O., Mahid, S. S., Hornung, C. A. \& Polk, H. C. Jr. Perioperative supplemental oxygen therapy and surgical site infection: a meta-analysis of randomized controlled trials. Arch. Surg. 144, 359-367 (2009).

85. Poldermans, D. et al. The effect of bisoprolol on perioperative mortality and myocardial infarction in high-risk patients undergoing vascular surgery. Dutch Echocardiographic Cardiac Risk Evaluation Applying Stress Echocardiography Study Group. N. Engl. J. Med. 341, 1789-1794 (1999).

86. Auerbach, A. \& Goldman, L. B-blockers and reduction of cardiac events in noncardiac surgery. JAMA 287, 1435-1444 (2002).

87. Lindenauer, P. K. et al. Perioperative betablocker therapy and mortality after major noncardiac surgery. N. Engl. J. Med. 353, 349-361 (2005)

88. Angeli, F. et al. Beta-blockers and risk of allcause mortality in non-cardiac surgery. Ther. Adv. Cardiovasc. Dis. 4, 109-118 (2010).

89. Hoeks, S. E. et al. Increase of 1-year mortality after perioperative beta-blocker withdrawal in endovascular and vascular surgery patients. Eur. J. Vasc. Endovasc. Surg. 33, 13-19 (2007).

90. Shammash, J. B. et al. Perioperative betablocker withdrawal and mortality in vascular surgical patients. Am. Heart J. 141, 148-153 (2001)

91. Psaty, B. M., Koepsell, T. D., Wagner, E. H., LoGerfo, J. P. \& Inui, T. S. Beta blockers and the primary prevention of nonfatal myocardial infarction in patients with high blood pressure. Am. J. Cardiol. 66, 12G-14G (1990).

92. Redelmeier, D., Scales, D. \& Kopp, A. Beta blockers for elective surgery in elderly patients: population based, retrospective cohort study. BMJ 331, 932 (2005).

93. Devereaux, P. J. et al. Effects of extendedrelease metoprolol succinate in patients undergoing non-cardiac surgery (POISE trial): a randomised controlled trial. Lancet $\mathbf{3 7 1}$, 1839-1847 (2008).

94. van Lier, F. et al. Impact of prophylactic beta-blocker therapy to prevent stroke after noncardiac surgery. Am. J. Cardiol. 105, 43-47 (2010).

95. Gould, M. K. et al. Prevention of VTE in nonorthopedic surgical patients: Antithrombotic Therapy and Prevention of Thrombosis, 9th ed: American College of Chest Physicians EvidenceBased Clinical Practice Guidelines. Chest 141, e227S-e277S (2012).

96. Kearon, C. Natural history of venous thromboembolism. Circulation 107, 122-130 (2003).

97. Comerota, A. J. et al. The fibrinolytic effects of intermittent pneumatic compression: mechanism of enhanced fibrinolysis. Ann. Surg. 226, 306-314 (1997).

98. Pannucci, C. J. et al. Identifying patients at high risk for venous thromboembolism requiring treatment after outpatient surgery. Ann. Surg. 255, 1093-1099 (2012). 
99. Geerts, W. H. et al. Prevention of venous thromboembolism: American College of Chest Physicians Evidence-Based Clinical Practice Guidelines (8th Edition). Chest 133, 381S-453S (2008).

100. Samama, C. M. et al. Venous thromboembolism prevention in surgery and obstetrics: clinical practice guidelines. Eur. J. Anaesthesiol. 23 95-116 (2006).

101. American Urological Association. Best Practice Statement for the Prevention of Deep Vein Thrombosis in Patients Undergoing Urologic Surgery [online], http://www.auanet.org/ content/media/dvt.pdf (2008).

102. Soderdahl, D. W., Henderson, S. R. \& Hansberry, K. L. A comparison of intermittent pneumatic compression of the calf and whole leg in preventing deep venous thrombosis in urological surgery. J. Urol. 157, 1774-1776 (1997).

103. Rice, K. R., Brassell, S. A. \& McLeod, D. G. Venous thromboembolism in urologic surgery: prophylaxis, diagnosis, and treatment. Rev. Urol. 12, e111-e124 (2010).

104. Delgado-Rodriguez, M. et al. Efficacy of surveillance in nosocomial infection control in a surgical service. Am. J. Infect. Control 29, 289-294 (2001)

105. Kasatpibal, N., Jamulitrat, S., Chongsuvivatwong, V., Norgaard, M. \& Sorensen, H. T. Impact of surgeon-specific feedback on surgical site infection rates in Thailand. J. Hosp. Infect. 63, 148-155 (2006).

106. Reilly, J. S. The effect of surveillance on surgical wound infection rates. J. Tissue Viability 9 , 57-60 (1999).

107. Haley, R. W. The scientific basis for using surveillance and risk factor data to reduce nosocomial infection rates. J. Hosp. Infect. 30 3-14 (1995).

108. Castella, A. et al. Surgical site infection surveillance: analysis of adherence to recommendations for routine infection contro practices. Infect. Control Hosp. Epidemiol. 27, 835-840 (2006).

109. Haley, R. W. et al. The efficacy of infection surveillance and control programs in preventing nosocomial infections in US hospitals. Am. J. Epidemiol. 121, 182-205 (1985).

110. McConkey, S. J. et al. Results of a comprehensive infection control program for reducing surgical-site infections in coronary artery bypass surgery. Infect. Control Hosp. Epidemiol. 20, 533-538 (1999).

111. Reilly, J. S., Baird, D. \& Hill, R. The importance of definitions and methods in surgical wound infection audit. J. Hosp. Infect. 47, 64-66 (2001).

112. Schneeberger, P. M., Smits, M. H., Zick, R. E. \& Wille, J. C. Surveillance as a starting point to reduce surgical-site infection rates in elective orthopaedic surgery. J. Hosp. Infect. 51, 179-184 (2002)

113. Starling, C. E., Couto, B. R. \& Pinheiro, S. M. Applying the Centers for Disease Control and Prevention and National Nosocomial Surveillance system methods in Brazilian hospitals. Am. J. Infect. Control 25, 303-311 (1997).

114. Lunn, J. N. The history and achievements of the National Confidential Enquiry into Perioperative Deaths. J. Qual. Clin. Pract. 18, 29-35 (1998).

115. Gray, A. United Kingdom national confidential enquiry into perioperative deaths. Minerva Anestesiol. 66, 288-292 (2000).

116. Hannan, E. L., Kilburn, H. Jr, Racz, M., Shields, E. \& Chassin, M. R. Improving the outcomes of coronary artery bypass surgery in New York State. JAMA 271, 761-766 (1994).

117. Wyse, R. K. \& Taylor, K. M. Using the STS and multinational cardiac surgical databases to establish risk-adjusted benchmarks for clinical outcomes. Heart Surg. Forum 5, 258-264 (2002).

118. Tu, J. V. \& Wu, K. The improving outcomes of coronary artery bypass graft surgery in Ontario, 1981 to 1995. CAMJ 159, 221-227 (1998).

119. Khuri, S. F. Safety, quality, and the National Surgical Quality Improvement Program. Am. Surg. 72, 994-1030 (2006).

120. Khuri, S. F. et al. The National Veterans Administration Surgical Risk Study: risk adjustment for the comparative assessment of the quality of surgical care. J. Am. Coll. Surg. 180, 519-531 (1995).

121. Khuri, S. F. et al. Risk adjustment of the postoperative mortality rate for the comparative assessment of the quality of surgical care: results of the National Veterans Affairs Surgical Risk Study. J. Am. Coll. Surg. 185, 315-327 (1997).

122. American College of Surgeons. National Surgical Quality Improvement Program (NSQIP) [online], http://www.acsnsqip.org/ (2008).

123. Khuri, S. F. The NSQIP: a new frontier in surgery. Surgery 138, 837-843 (2005).

124. Celso, B. et al. A systematic review and metaanalysis comparing outcome of severely injured patients treated in trauma centers following the establishment of trauma systems. J. Trauma 60 , 371-378 (2006).

125. Jurkovich, G. J. \& Mock, C. Systematic review of trauma system effectiveness based on registry comparisons. J. Trauma 47, S46-S55 (1999).

126. Mock, C., Joshipura, M., Goosen, J. \& Maier, R. Overview of the Essential Trauma Care Project. World J. Surg. 30, 919-929 (2006).

127. Mock, C., Quansah, R., Krishnan, R. Arreola-Risa, C. \& Rivara, F. Strengthening the prevention and care of injuries worldwide. Lancet 363, 2172-2179 (2004).

128. Mock, C. N., Quansah, R., Addae-Mensah, L. $\&$ Donkor, P. The development of continuing education for trauma care in an African nation. Injury 36, 725-732 (2005).

129. Mock, C., Joshipura, M., Goosen, J., Lormand, J. D. \& Maier, R. Strengthening trauma systems globally: the Essential Trauma Care Project. J. Trauma 59, 1243-1246 (2005).

130. Mock, C. Improving prehospital trauma care in rural areas of low-income countries. J. Trauma 54, 1197-1198 (2003).

131. MacKenzie, E. J. et al. A national evaluation of the effect of trauma-center care on mortality. N. Engl. J. Med. 354, 366-378 (2006).

132. Begg, C. B., Cramer, L. D., Hoskins, W. J. \& Brennan, M. F. Impact of hospital volume on operative mortality for major cancer surgery. JAMA 280, 1747-1751 (1998).

133. Schrag, D. et al. Influence of hospital procedure volume on outcomes following surgery for colon cancer. JAMA 284, 3028-3035 (2000).

134. Bach, P. B. et al. The influence of hospital volume on survival after resection for lung cancer. N. Engl. J. Med. 345, 181-188 (2001).

135. Hershman, D. et al. Timing of adjuvant chemotherapy initiation after surgery for stage III colon cancer. Cancer 107, 2581-2588 (2006).

136. Govindarajan, A. et al. Population-based assessment of the surgical management of locally advanced colorectal cancer. J. Natl Cancer Inst. 98, 1474-1481 (2006).

137. Baxter, N. N. et al. Lymph node evaluation in colorectal cancer patients: a population-based study. J. Natl Cancer Inst. 97, 219-225 (2005).
138. Cummings, L. C., Payes, J. D. \& Cooper, G. S. Survival after hepatic resection in metastatic colorectal cancer: a population-based study. Cancer 109, 718-726 (2007).

139. Malthaner, R. \& Fenlon, D. Preoperative chemotherapy for resectable thoracic esophageal cancer. Cochrane Database Syst. Rev. Issue 4. Art. No.: CD001556 (2003).

140. Surgical Care Outcomes Assessment Program (SCOAP). A program of the foundation for health care quality [online], http://www.scoap.org (2012).

141. Flum, D. R. et al. Washington State's approach to variability in surgical processes/Outcomes: Surgical Clinical Outcomes Assessment Program (SCOAP). Surgery 138, 821-828 (2005)

142. Kwon, S. et al. Creating a learning healthcare system in surgery: Washington State's Surgical Care and Outcomes Assessment Program (SCOAP) at 5 years. Surgery 151, 146-152 (2012)

143. Weiser, T. G. et al. Standardised metrics for global surgical surveillance. Lancet $\mathbf{3 7 4}$, 1113-1117 (2009).

144. Gladwell, M. Outliers: The Story of Success (Little, Brown and Co., New York, USA, 2008).

145. Aggarwal, R. et al. Proving the effectiveness of virtual reality simulation for training in laparoscopic surgery. Ann. Surg. 246, 771-779 (2007)

146. Crochet, P. et al. Deliberate practice on a virtual reality laparoscopic simulator enhances the quality of surgical technical skills. Ann. Surg. 253, 1216-1222 (2011)

147. Ericsson, K. A., Nandagopal, K. \& Roring, R. W. Toward a science of exceptional achievement: attaining superior performance through deliberate practice. Ann. NY Acad. Sci. 1172 199-217 (2009)

148. Hu, Y. Y. et al. Postgame analysis: using videobased coaching for continuous professional development. J. Am. Coll. Surg. 214, 115-124 (2012).

149. Lendvay, T. S. Surgical simulation in pediatric urologic education. Curr. Urol. Rep. 12, 137-143 (2011).

150. Wignall, G. R. et al. Surgical simulation: a urological perspective. J. Urol. 179, 1690-1699 (2008)

151. Ghaferi, A. A., Birkmeyer, J. D. \& Dimick, J. B. Variation in hospital mortality associated with inpatient surgery. N. Engl. J. Med. 361, 1368-1375 (2009).

152. Funk, L. M. et al. Esophagectomy outcomes at low-volume hospitals: the association between systems characteristics and mortality. Ann. Surg. 253, 912-917 (2011).

153. Finks, J. F., Osborne, N. H. \& Birkmeyer, J. D. Trends in hospital volume and operative mortality for high-risk surgery. N. Engl. J. Med. 364, 2128-2137 (2011)

154. Haynes, A. B. et al. A surgical safety checklist to reduce morbidity and mortality in a global population. N. Engl. J. Med. 360, 491-499 (2009)

155. Weiser, T. G. et al. Effect of a 19-item surgical safety checklist during urgent operations in a global patient population. Ann. Surg. 251, 976-980 (2010)

156. de Vries, E. N. et al. Effect of a comprehensive surgical safety system on patient outcomes. N. Engl. J. Med. 363, 1928-1937 (2010).

157. van Klei, W. A. et al. Effects of the introduction of the WHO "Surgical Safety Checklist" on inhospital mortality: a cohort study. Ann. Surg. 255, 44-49 (2012). 
158. Birkmeyer, J. D. Strategies for improving surgical quality-checklists and beyond. N. Engl. J. Med. 363, 1963-1965 (2010).

159. Neily, J. et al. Association between implementation of a medical team training program and surgical mortality. JAMA 304, 1693-1700 (2010).

160. de Leval, M. R., Carthey, J., Wright, D. J. Farewell, V. T. \& Reason, R. T. Human factors and cardiac surgery: a multicenter study. J. Thorac Cardiovasc. Surg. 119, 661-672 (2000).

161. Carthey J., de Leval, M. R. \& Reason, J. T. The human factor in cardiac surgery: errors and near misses in a high technology medical domain. Ann. Thorac. Surg. 72, 300-305 (2001).

162. Stulberg, J. J. et al. Adherence to surgical care improvement project measures and the association with postoperative infections. JAMA 303, 2479-2485 (2010).

163. Weiser, T. G. Health policy: All-or-none compliance is the best determinant of quality of care. Nat. Rev. Urol. 7, 541-542 (2010).

164. Levy, S. M. et al. Implementing a surgical checklist: more than checking a box. Surgery 152, 331-336 (2012).

165. Weiser, T. G. et al. Perspectives in quality: designing the WHO Surgical Safety Checklist. Int. J. Qual. Health Care 22, 365-370 (2010).

166. Center for the History of Medicine at Countway Library. Ernest Amory Codman (Boston Medical Library, Boston, USA, 2011).

167. Reason, J. Human Error (Cambridge University Press, Cambridge, UK, 1992).
168. World Health Organization (WHO). WHO Surgical Safety Checklist [online], http://www.who.int/ patientsafety/safesurgery/en/ (2009).

169. Collins, T. \& Lipke, G. Reducing VAP in your hospital: three practice changes that may be the recipe for success [online], http://

www.rtmagazine.com/all-news/16564reducing-vap-in-your-hospital-three-practicechanges-that-may-be-the-recipe-for-success (2009).

Author contributions

T. G. Weiser and M. P. Porter researched, wrote, discussed, reviewed, and edited this article.

R. V. Maier made substantial contributions towards discussions of content and reviewed and edited the article prior to submission. 